\title{
Além do tema, também professor!
}

Resumo: A folclorista Raquel Trindade, filha do poeta, escritor e ativista negro Solano Trindade, leva em frente o trabalho do pai na preservação e renovação da cultura negra no Brasil - por meio de atividades que envolvem diversas formas de arte, entre elas dança, artes cênicas e música. Neste depoimento, ela conta sobre a história de sua família e do estabelecimento de raízes no interior paulista, sobre sua trajetória como artista e ativista e sobre o desafio e a importância de se manter viva a cultura negra no Brasil.

Palavras-chave: Cultura negra, música, dança, teatro, Raquel Trindade.
Abstract: The folklorist Raquel Trindade, daughter of the poet, writer and black activist Solano Trindade, takes ahead his father's work focused in the black culture preservation and renewal in Brazil - through activities that involve several art forms, including dance, theater arts and music. She relates, in this declaration, about her family story and how they put down roots in São Paulo State country-side, about her trajectory as an artist and an activist, about the challenge and the importance of keeping alive the black culture in Brazil.

Keywords: Black culture, music, dance, theater, Rachel Trindade.

A cultura negra não é apenas motivo de pesquisa; pode e deve, também, inspirar modelos de ensino sobre as tradições e histórias do povo brasileiro. Assim comprova a trajetória de Raquel Trindade, considerada uma das principais griôs - guardiões do conhecimento na cultura negra - vivas no país. Filha do poeta, escritor e ativista negro Solano Trindade, é fundadora do Teatro Popular que leva o nome do pai, na cidade paulista de Embu das Artes, local cuja história também se confunde com a sua própria. Ali, os grupos de dança do Teatro mantêm vivos os ritmos e as músicas originais trazidos da África - como maracatu, coco, jongo, samba de roda, bumba meu boi e lundu. Em ações culturais na comunidade ou procurando vencer o desafio de inserir o tema da cultura negra em ambiente escolar, Raquel leva a sério as palavras do pai em um de seus últimos poemas: "Estou conservado no ritmo do meu povo. Me tornei cantiga determinadamente e nunca terei tempo para morrer"*.

Nasci em Pernambuco, meu pai também. Moramos em muitos lugares antes de vir aqui ao Embu. Passamos por Rio de Janeiro, São Paulo, com meu pai sempre atuando na militância política. No Rio de Janeiro, em 1950, ele criou, ao lado de minha mãe Maria Margarida e do sociólogo Edison Carneiro, o Teatro Popular Brasileiro. E depois do falecimento dele, em 1974, criei o Teatro Popular Solano Trindade, que foi registrado formalmente em 1980, já no centro de Embu.

No teatro, que não tinha ainda um prédio, mas se caracterizava por um movimento cultural, passei a ensinar as danças que meus pais tinham me ensinado:

* Com a colaboração de Juliana Winkel. 


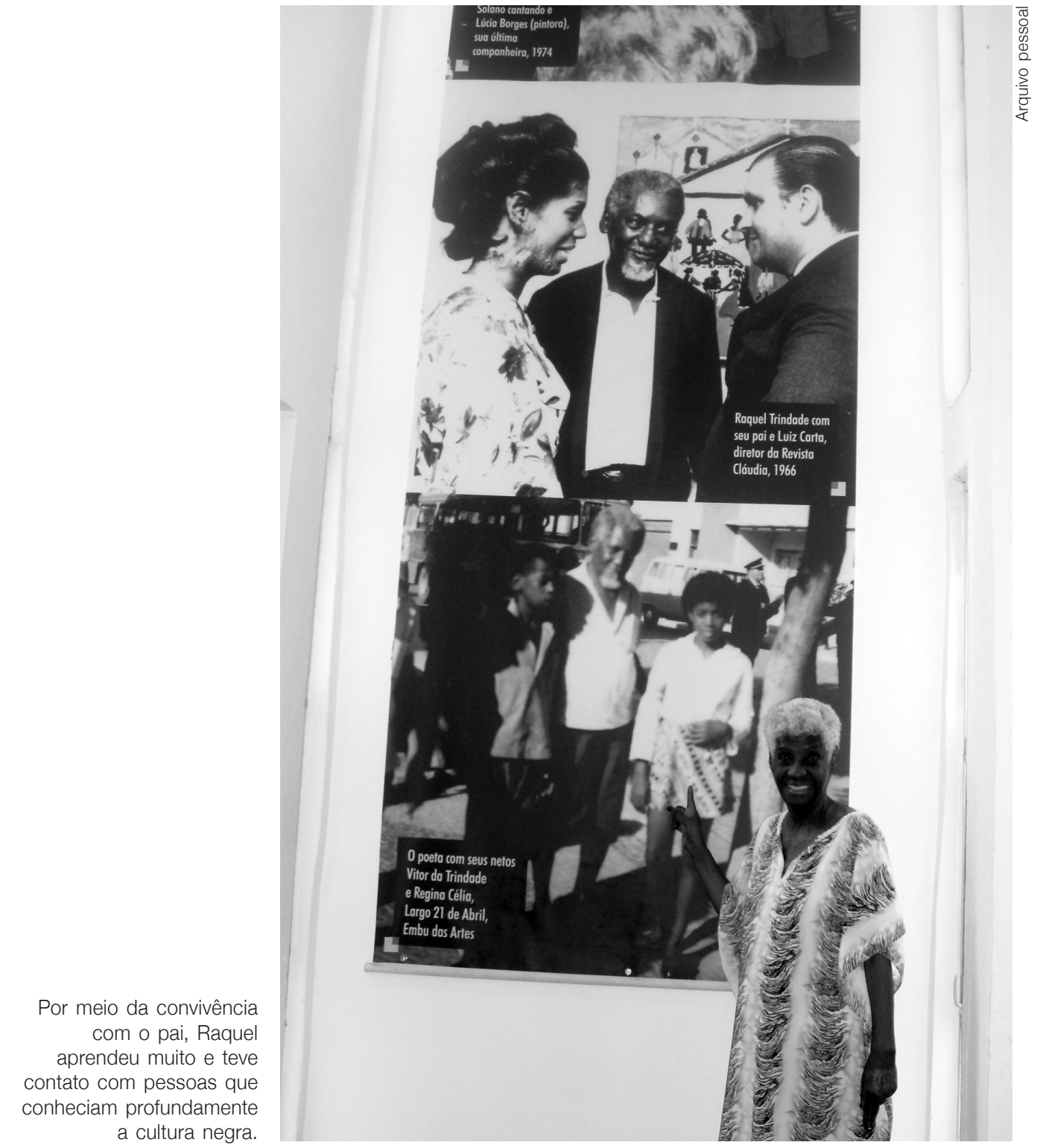

maracatu, coco, lundu, jongo, samba-lenço rural paulista, jongo mineiro, jongo fluminense, bumba meu boi de Pernambuco, guerreiros de Alagoas. Todas as danças que trazem a herança do folclore nacional. Alguns anos depois, nosso grupo de dança ganhou um terreno da Prefeitura e construímos um barracão para ensaiarmos. Depois conseguimos uma verba do Estado, enviada por meio da Prefeitura da cidade, e foi então construído o primeiro prédio do teatro.

Tínhamos, porém, diversos problemas com chuvas. Uma parede chegou inclusive a cair devido a vazamentos. Além de desejar melhorar a estrutura do teatro, tínhamos também o sonho de ter um estúdio de gravação. Meu filho Victor da Trindade, meus netos Manuel, Zinho Trindade e Carlos Caçapava são músicos. Do próprio teatro saíram várias bandas, e mesmo eu sempre quis gravar o repertório do grupo. Então, há cerca de um ano, o Ministério do Turismo enviou para a Caixa Econômica Federal do Embu, via Prefeitura 
Além do tema, também professor! - Juliana Winkel

Municipal, a verba para restaurar e ampliar o teatro. Em novembro (2010), iremos reinaugurá-lo com uma grande festa organizada por meu filho Victor da Trindade e por meu neto Marcelo Thomé, que é circense e cuida da administração do teatro.

Com a reforma, ele se amplia e ganha um estúdio, dois camarins, a instalação da cabine de luz e som e melhorias da questão acústica. O palco será ampliado e haverá um anfiteatro para que as pessoas assistam aos espetáculos. Além disso, o teatro seguirá todas as normas de segurança e acessibilidade, incluindo rampas para pessoas com deficiência. Abrigará todas as aulas já dadas atualmente - de percussão, hip-hop, capoeira angola, danças brasileiras, construção e pesquisa de instrumentos africanos e afro-brasileiros.

Tudo isso é continuação do trabalho de minha família, desde meus avós no Recife. Meu avô era velho de pastoril, minha avó fazia lapinha no Natal, minha outra avó por parte de mãe dançava maracatu. Minha mãe era evangélica, terapeuta ocupacional - mas foi ela quem me ensinou todas as danças, com exceção do candomblé, que eu vim a conhecer depois. Meu pai era marxista, comunista, e minha mãe presbiteriana. E participo do candomblé há mais de quarenta anos. Tenho uma filha que é evangélica batista, atualmente morando no Rio, e outra filha que faz faculdade nos Estados Unidos e é budista. Eu e meu filho Victor somos do candomblé e minha nora Elis é católica. E todos nos damos bem, um respeita o espaço do outro.

\section{TRADIÇÃO NAS NOVAS GERAÇÕES}

Toda a comunidade frequenta nossos cursos, que são gratuitos. A cultura que difundimos é negra, mas voltada para todas as etnias. Temos descendentes de japoneses, brancos, descendentes de índios e negros - dos dez aos setenta anos. Vêm muitos estrangeiros também, para ter aulas de percussão. Desde 2009,

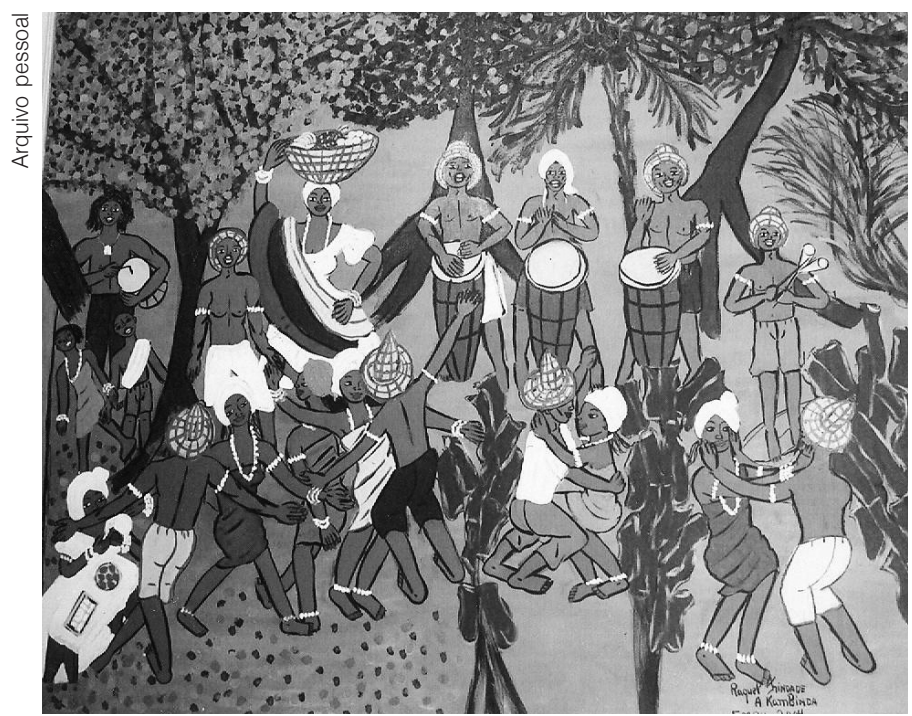

Quadro pintado por Raquel. somos Ponto de Cultura, reconhecido pelo Ministério da Cultura.

Há cinco anos, fundamos também aqui o bloco do Kambinda. Nele, expresso um pouco da minha longa vivência no samba. Fui vice-campeã da Escola de Samba Vai-Vai duas vezes - a primeira com o enredo "Solano Trindade - o moleque do Recife", com versos de Geraldo Filme, depois com "José 
comunicação \& educação • Ano XVI • número 1 • jan/jun 2011

Maurício, músico do Brasil Colonial”. Depois fui convidada pelo sambista Candeia para fazer o Carnaval da Escola de Samba Quilombo, criada por ele no Rio de Janeiro em 1978. Fiz o enredo "Ao povo em forma de arte", com base no lema de meu pai: Pesquisar na fonte de origem e devolver ao povo em forma de arte. Esse samba foi campeão com Wilson Moreira e Nei Lopes. Depois disso, fiz vários sambas-enredo para escolas até que, junto com o Maninho da Cuíca, primeiro sambista do Embu, decidimos criar um bloco aqui na casa - que, neste último ano de 2010, saiu com mais de cem pessoas.

Os jovens, as novas gerações, têm muito interesse pela cultura negra. Só aqui no Teatro, vemos surgir várias manifestações culturais novas. Foi organizado um grupo, Capulanas, que mistura dança e poesia. Da mesma forma, os meninos do hip-hop desenvolvem seu próprio estilo. Claro que o hip-hop não é brasileiro, mas é um ritmo que já se abrasileirou. O que é o MC? É um repentista. Meu neto Zinho da Trindade é um repentista que coloca isso, modernamente, no hip-hop. Aqui cultuamos muito as tradições, mas também temos os olhos abertos para as coisas novas de boa qualidade. E estes que citei conseguem fazer com qualidade as duas coisas - o novo e o antigo.

No Teatro atendemos a escolas, universidades, jornalistas. As pessoas vão à Secretaria da Cultura da Prefeitura da cidade, para saber a história do Embu, e eles pedem que venham conversar comigo. Escrevi em 2003 o livro Embu Aldeia de M'Boy, sobre a história da cidade, pela Editora Noovha América, e finalizei outro que será lançado em breve pela mesma editora, com o apoio da Secretaria da Educação - falando sobre a história, a vida cultural, os artistas do Embu.

Posso dizer que, de fato, ajudamos a construir a história cultural do Embu. Depois de morarmos no Recife e no Rio de Janeiro, passamos uma temporada na Europa com o grupo de dança de meu pai. Dançamos por toda a Polônia, toda a antiga Tchecoslováquia. E, quando voltamos ao Brasil, organizamos um espetáculo em São Paulo. Aqui já estavam os escultores Tadakiyo Sakai, Cássio M'Boi, Claudionor Assis Dias. Foi quando o Sakai disse ao Assis que ele, sendo negro e escultor, deveria conhecer Solano Trindade, para entender mais sobre a cultura negra e aplicá-la como temática em seu trabalho. Então Assis foi assistir a um espetáculo de nosso grupo e gostou muito, participando inclusive. Fez amizade com meu pai e trouxe a nós todos para conhecer o Embu.

Isso aconteceu em 1961. E o Embu, naquela época, era ainda mais bonito do que é hoje. O rio Embu-mirim tomava o terreno quase todo com água mineral pura. A região era cheia de árvores, não havia a maioria das casas de hoje. A cidade era formada praticamente pelo centro colonial e pela cachoeira, o rio e a lagoa limpos. Nós adoramos o lugar e fomos todos para o barraco do Assis. Ele e a esposa, Imaculada, tinham várias crianças. Nós dormíamos todos pelo chão e fazíamos festas culturais, religiosas, que duravam três dias ao redor da lagoa. Não fomos mais embora.

O movimento cultural que existia, ao lado dos artistas que já estavam aqui, foi atraindo cada vez mais gente para o Embu. Logo foram criados os salões de 
arte. Mais tarde, quando foi organizada a feira da Praça da República, em São Paulo, comecei a ir para lá também. E o Assis, com medo de que o movimento na Praça da República enfraquecesse as atividades no Embu, criou a feira da Praça do Embu. Começaram então a vir para cá todos os artistas. Nessa época não havia Secretaria de Turismo, iniciativa formal, nada disso. Nós criamos a Secretaria de Turismo. E atualmente estamos nos preparando para o plebiscito que haverá no ano que vem, pelo qual se decidirá se o Embu, considerado estância turística, ganhará o nome oficial de Embu das Artes - o que ele já é espontaneamente.

\section{CULTURA QUE É DE TODOS}

Percebemos o aumento de interesse pela cultura negra desde a década de 1950, quando morávamos no Rio de Janeiro. Na época em que eu era menina, já havia o Teatro Experimental do Negro, fundado por Abdias do Nascimento. Havia também a Orquestra Afro-brasileira, criada pelo maestro Abigail Moura, e o balé Afro, de Mercedes Batista, a primeira bailarina negra do Teatro $\mathrm{Mu}$ nicipal. Meu pai e minha mãe ajudaram a criar o teatro folclórico do escritor e produtor Aroldo Costa, logo antes de criarem o Teatro Popular Brasileiro. Ou seja, a luta vem de muito tempo, apesar da discriminação muito grande, inclusive da mídia.

Na verdade, sempre recebemos um bom apoio dos jornais impressos. Já as emissoras de televisão abrem um pouco menos de espaço, com exceção da TV

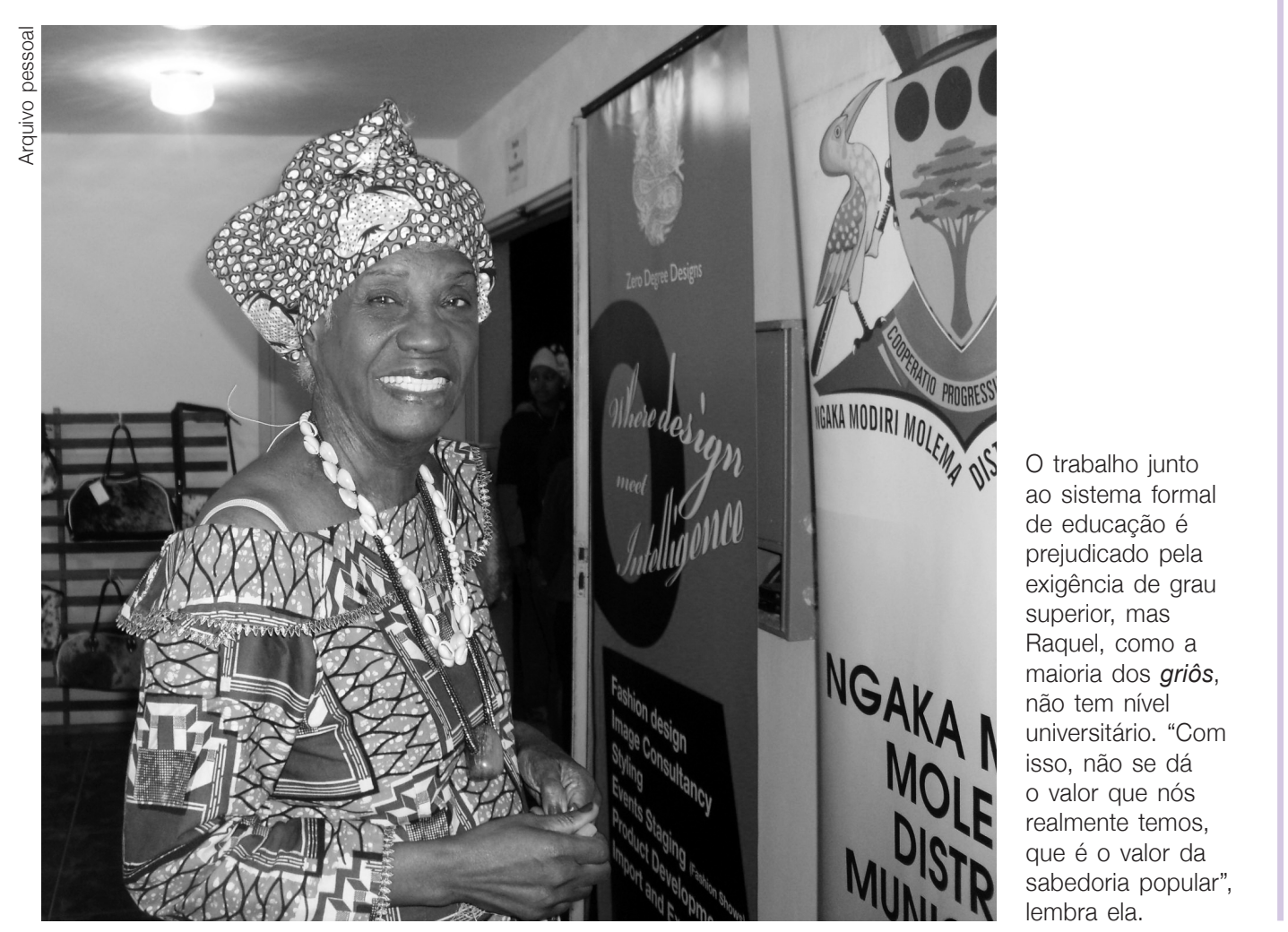


Futura e da TV Cultura, além da TV SESC. Temos um bom relacionamento com a Rede SESC: costumamos nos apresentar em praticamente todas as unidades de São Paulo. Aos poucos, vemos o espaço se abrindo. Mas ainda não é o ideal - ainda se toca muita música estrangeira, se dá muito destaque para o que vem de fora do país, e pouco para a nossa cultura propriamente.

Mesmo entre as escolas o interesse vem crescendo, inclusive anterior à lei que determina o ensino da história negra em sala de aula. Em 1987, por exemplo, fui convidada por Antônio Nóbrega para dar aulas sobre dança e artes cênicas na Unicamp, onde trabalhei de 1987 a 1992. Comecei a lecionar como técnica didata e depois passei a professora. Ali percebi que, dentro do curso de graduação em artes cênicas, só havia um negro. Então, organizamos na Unicamp um curso de extensão abordando o folclore e a cultura negra. Tivemos grupos de alunos da comunidade de Campinas e de outras graduações. Essa reunião de interessados deu origem ao grupo de dança e resgate da cultura Urucungos, Puitas e Quijêngues, que existe até hoje - de nome inspirado em instrumentos bantos que foram trazidos pelos escravos para São Paulo. O Urucungo equivale ao berimbau, as puítas, às cuícas, e os quijêngues, aos tambores.

Apesar do sucesso do curso, porém, eu sentia certa discriminação do meio acadêmico por não ter nível universitário. Na época, estava tratando um câncer e me separando de meu último marido. Foram questões demais para administrar. Decidi, dessa forma, pedir demissão da Universidade e voltar para o Embu. Desde então, mantenho o trabalho aqui e tenho dado também muitas palestras.

Atualmente, temos um projeto em análise há quase um ano junto à Prefeitura do Embu, propondo aulas de cultura negra para os professores e educadores em geral, em parceria com a Secretaria Municipal da Educação. A própria formação dos educadores é uma necessidade que se reforça com a entrada do tema nas escolas. Pretendemos, no curso, abordar a África Pré-colonial, os sistemas de escrita que já existiam, a primeira operação de cérebro, realizada ainda no Egito antigo. Discutiremos os costumes e fatos importantes ligados à história negra e, numa segunda etapa, as personalidades brasileiras - os grandes líderes, escritores, poetas, pintores e escultores negros. Também as religiões que vieram com eles, a culinária e, por meio de atividades práticas, as danças. Para me auxiliar nesta parte prática, tenho uma equipe de três ritmistas, incluindo meus netos Manoel Trindade e Zinho Trindade, além da dançarina Karla Magalhães.

Acredito que o interesse pela cultura negra cresça ainda mais daqui em diante. Como sempre existiu muito preconceito, não houve até hoje preocupação em saber a história do negro. Nas escolas, o assunto sempre esteve restrito à escravidão. E sempre se falou da Lei Áurea como se tivesse sido dada de presente para nós, quando na verdade houve muita luta anterior. Tudo isso faz com que as pessoas se interessem pouco pela história do negro. 
$\mathrm{Eu}$, por exemplo, estou há um ano tentando trabalhar junto ao sistema formal de educação, mas a concretização dos projetos esbarra no fato de eu não ter nível universitário. Acontece que, como eu, a maioria dos griôs não tem nível universitário. Com isso, não se dá o valor que eles têm realmente, que é o valor da sabedoria popular. Minha sorte foi que tive um pai fantástico, que era autodidata, pesquisava muito e me transmitiu muita coisa. Por meio da convivência com ele, aprendi muito e tive contato com pessoas que conheciam profundamente a cultura negra: Edison Carneiro, Roger Bastide. Desde então, tudo que sei procuro transmitir aos outros, seja por meios teóricos, seja pela dança e pela música. E estou aprendendo ainda, com todos os que passam por aqui. Ao lidar com a cultura, a gente aprende todos os dias. 


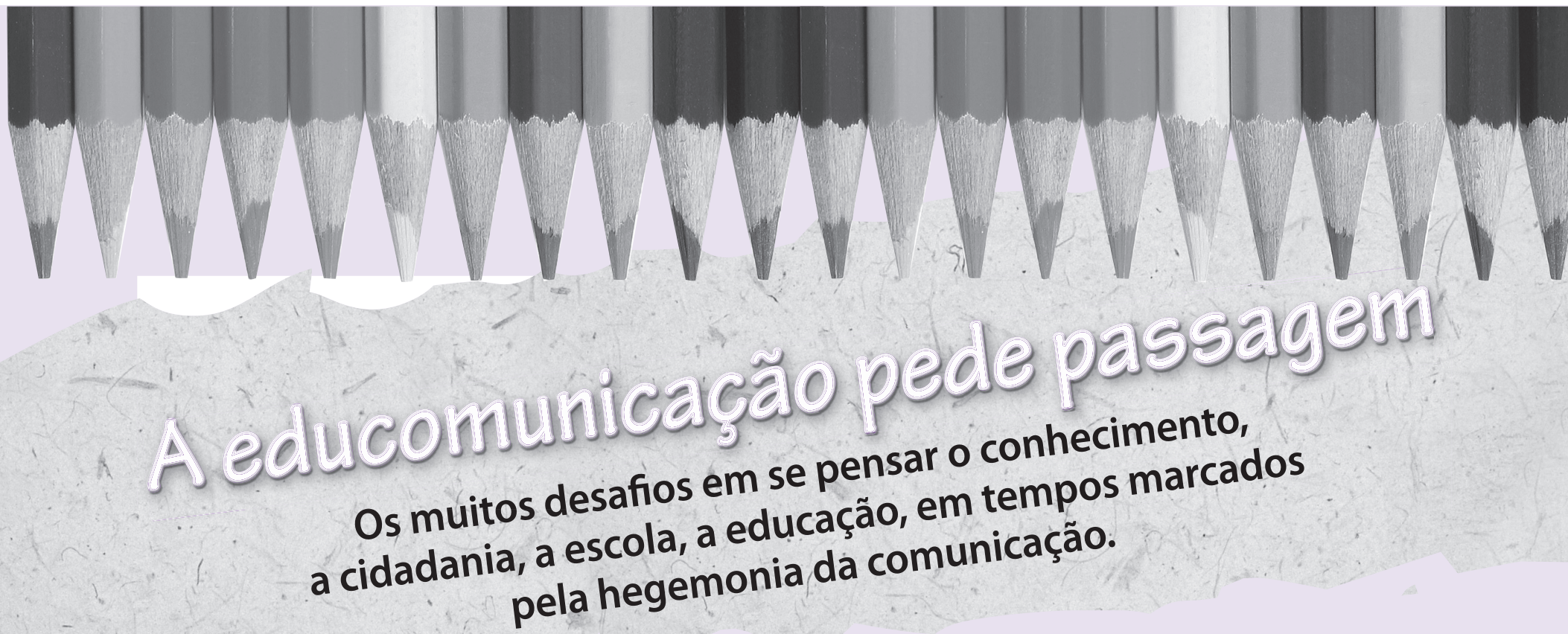

Área do conhecimento que busca pensar, pesquisar e trabalhar a educação formal, informal e não formal a partir de ecossistemas comunicativos, o termo "educomunicação" ganha lugar e vitalidade. A comunicação deixa de ser vista como fenômeno tão somente midiático, de função instrumental, para integrar dinâmicas formativas e planos de aprendizagem, como assistir à televisão e ao cinema, ler o jornal e a revista, produzir programas audiovisuais e em mídias digitais.

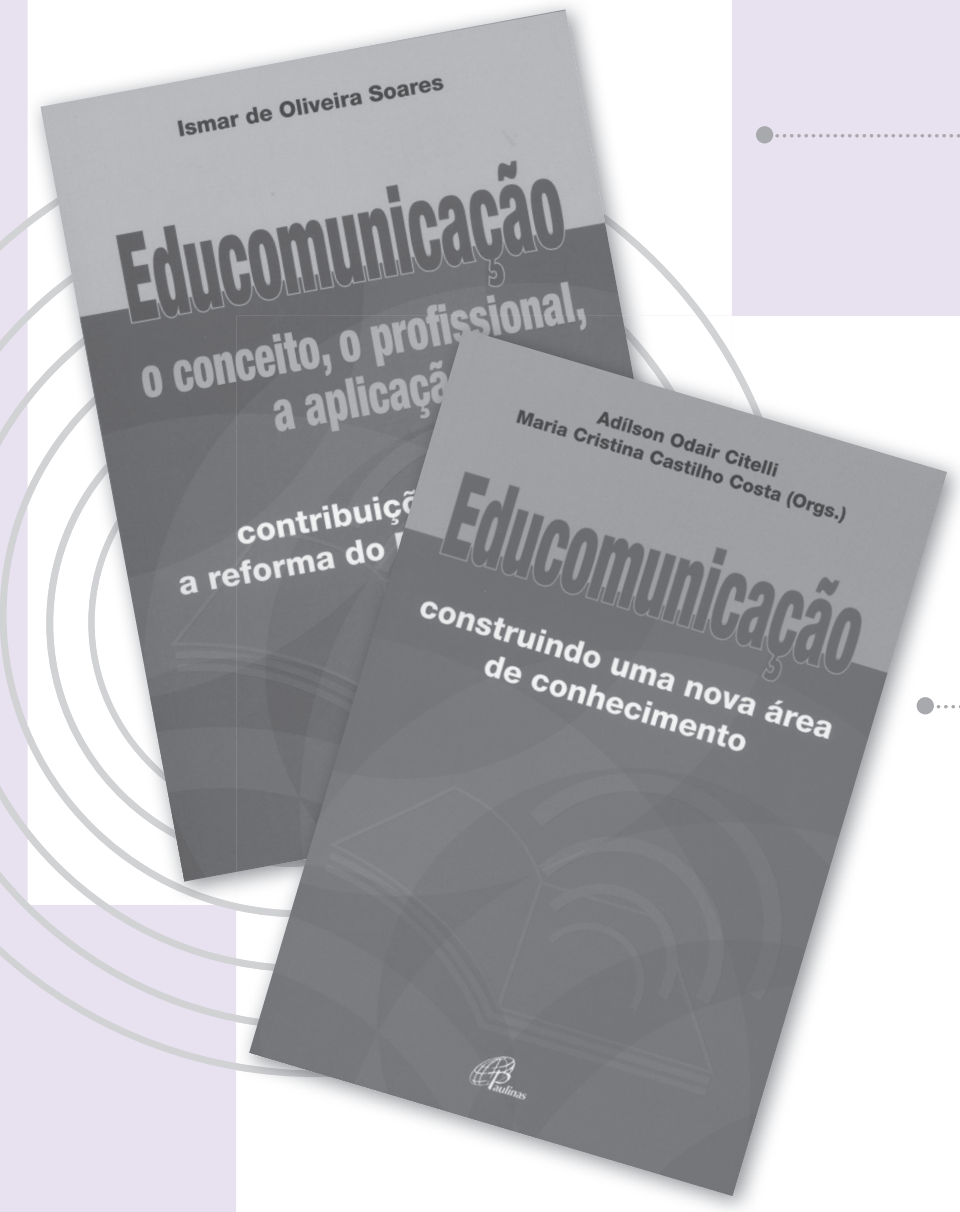

EDUCOMUNICAÇÃO: o conceito, o profissional, a aplicação contribuições para a reforma do Ensino Médio

Ismar de Oliveira Soares

104 págs. | Cód.: 518298 | ISBN: 9788535627527

A escola hoje repele e joga contra as experiências mais interessantes que a adolescência proporciona ao indivíduo. Está distante do jovem. Obra propõe um debate sobre a relação entre juventude, educação e práticas educomunicativas no contexto das discussões sobre a política educacional proposta pelo MEC.

\section{EDUCOMUNICAÇÃO}

construindo uma nova área de conhecimento

Adílson Odair Citelli e Maria Cristina Castilho Costa (orgs.)

256 págs. | Cód.: 518239 | ISBN: 9788535627466

Especialistas nesse novo campo do conhecimento escreveram artigos originalmente publicados na revista Comunicação \& Educação, único veículo brasileiro a tratar o tema de forma sistemática por quase quinze anos. Coletânea reúne os mais relevantes ensaios que buscaram dar corpo e forma à inter-relação entre a comunicação e a educação, buscando conceituar, discutir e problematizar a Educomunicação. São oito ensaios de autores brasileiros, cinco de pesquisadores estrangeiros e quatro entrevistas com pesquisadores, professores e participantes de movimentos sociais. 